\title{
Review of: "Need for cognition moderates the impairment of decision making caused by nightshift work in nurses"
}

\author{
Hikaru Hori ${ }^{1}$ \\ 1 University of Occupational and Environmental Health, Japan
}

Potential competing interests: The author(s) declared that no potential competing interests exist.

This study shows the fatigue level and decision making ability of female nurses after night shift using IGT. This study is very interesting although it has some limitations.

My comments are listed below.

1) The background information is insufficient. Please describe the factors that affect decision-making ability. For example, please describe educational history and medications.

2) Some diseases are known to decrease the IGT. Please cite the following references and state that you have excluded these diseases.

(1)The lowa Gambling Task in Parkinson's disease: A meta-analysis on effects of disease and medication. Evens R, Hoefler M, Biber K, Lueken U.Neuropsychologia. 2016 Oct;91:163-172. doi:

10.1016/j.neuropsychologia.2016.07.032. Epub 2016 Jul 27.

(2) Decision making measured by the lowa Gambling Task in alcohol use disorder and gambling disorder: a systematic review and meta-analysis. Kovács I, Richman MJ, Janka Z, Maraz A, Andó B. Drug Alcohol Depend. 2017 Dec 1;181:152-161. doi: 10.1016/j.drugalcdep.2017.09.023. Epub 2017 Oct 12.

(3) Decision-making in obesity without eating disorders: a systematic review and meta-analysis of lowa gambling task performances. Rotge JY, Poitou C, Fossati P, Aron-Wisnewsky J, Oppert JM.Obes Rev. 2017 Aug;18(8):936-942. doi: 10.1111/obr.12549. Epub 2017 Apr 21.

(4) lowa Gambling Task performance in euthymic bipolar I disorder: a meta-analysis and empirical study. Edge MD, Johnson SL, Ng T, Carver CS.J Affect Disord. 2013 Aug 15;150(1):115-22. doi:

10.1016/j.jad.2012.11.027. Epub 2012 Dec 7.

(5) Deciphering reward-based decision-making in schizophrenia: A meta-analysis and behavioral modeling of the lowa Gambling Task. Betz LT, Brambilla P, Ilankovic A, Premkumar P, Kim MS, Raffard S, Bayard S, Hori H, Lee KU, Lee SJ, Koutsouleris N, Kambeitz J. Schizophr Res. 2019 Feb;204:7-15. doi:

10.1016/j.schres.2018.09.009. Epub 2018 Sep 25.

(6) Impaired decision-making in symptomatic anorexia and bulimia nervosa patients: a meta-analysis. Guillaume S, Gorwood P, Jollant F, Van den Eynde F, Courtet P, Richard-Devantoy S. Psychol Med. 2015 Dec;45(16):3377-91. doi: 10.1017/s003329171500152x.

3) The following report shows that depressive symptoms affect IGT performance. Please cite the following 
article and describe how depressive symptoms were assessed in this study.

Relationships between brain-derived neurotrophic factor, clinical symptoms, and decision-making in chronic schizophrenia: data from the lowa Gambling Task.

Hori H, Yoshimura R, Katsuki A, Atake K, Nakamura J.Front Behav Neurosci. 2014 Dec 4;8:417. doi: 10.3389/fnbeh.2014.00417. eCollection 2014.

I hope my comments will be helpful. 